\title{
Familial invasive and in situ squamous cell carcinoma of the skin
}

\author{
K Hemminki*,',2, H Zhang' and K Czene' \\ 'Department of Biosciences at Novum, Karolinska Institute, 14157 Huddinge, Sweden; '2Division of Molecular Genetic Epidemiology, German Cancer \\ Research Center (DKFZ), Heidelberg, Germany
}

\begin{abstract}
We used the updated nation-wide Swedish Family-Cancer Database to examine familial risks in data from 1961 to 1998 on 1252 invasive and 2474 in situ squamous cell carcinoma (SCC) of the skin among offspring, and over 10 times more among parents. In 259 families a parent and an offspring had skin SCC. The familial standardised incidence ratios (SIRs) were 2.72 for invasive and 2.40 for in situ skin cancers in offspring. Multiple skin cancers in parents were associated with increased SIRs for invasive SCC in offspring, being 2.55 for one and up to 14.93 for two invasive and two in situ cancers in parents; the corresponding in situ SCC risks were 2.28 and 7.49. The population attributable fraction for any familial skin SCC, invasive or in situ, was 4. I\%. Melanoma was the only discordant tumour that was associated with invasive and in situ skin SCC. These results provide evidence that there is an underlying hereditary susceptibility for at least a part of the familial clustering for skin SCC.

British Journal of Cancer (2003) 88, I375-1380. doi:I0.1038/sj.bjc.6600909 www.bjcancer.com

(c) 2003 Cancer Research UK
\end{abstract}

Keywords: multiple skin cancer; multiple skin cancers; Bowen's disease; in situ carcinoma

Squamous cell carcinoma (SCC) of the skin is not recorded by most cancer registries and its established risk factors are limited to fair skin, ultraviolet light, arsenic compounds and immunosuppression, while less is known about benign lesions, such as actinic keratosis and in situ carcinoma (intraepidermal SCC, or Bowen's disease) (IARC, 1990, 1995; English et al, 1997) The Swedish Cancer Registry has recorded both invasive and in situ SCC whose incidence has rapidly increased over the past 20 years (Center for Epidemiology, 2000; Wassberg et al, 2001). Skin SCC is the fourth most common cancer in men and women in Sweden in 1998, and the in situ form is the most common benign/precancerous tumour in men and the second among women after in situ cervical cancer. In situ skin cancer does not appear to be a simple precursor lesion to invasive SCC because the age of onset of the two forms is similar; a true precursor lesion would be expected to show an earlier age of onset, as with cervical in situ and invasive cancers (MacKie, 1996; Reese, 1998, 2002; Hemminki et al, 1999; Heaphy and Ackerman, 2000; Hemminki and Dong, 2000c; Rees, 2002).

We have previously reported on familial skin cancer from the nation-wide Swedish Family-Cancer Database (Hemminki and Dong, 2000a). In comparisons of familial cancers at many sites in the Database, the standardised incidence ratio (SIR) for invasive skin cancer (2.4) was intermediate, but, it exceeded that for breast (SIR 1.85) and colon (1.89) cancers (Dong and Hemminki, 2001a). We have used the most recent update of the nation-wide Swedish Family-Cancer Database, covering 10.2 million individuals and over 1.0 million tumours to investigate familial relations of invasive and in situ SCC. Association of skin SCC with other cancers in families is also described. In contrast to our previous study, the number of cases has almost doubled in the offspring

\footnotetext{
*Correspondence: Dr K Hemminki, CNT Novum, 14I 57 Huddinge, Sweden; E-mail: kari.hemminki@cnt.ki.se

Received 23 December 2002; revised 3 February 2003; accepted 14 February 2003
}

generation, allowing separate analyses for familial risks by invasive and in situ SCC, as well as by multiple skin tumours.

\section{SUBJECTS AND METHODS}

The subjects were identified from the Family-Cancer Database, where the first generation (parents) was regarded as probands and familial risks were calculated for the second generation (offspring). We analysed the risk of invasive and in situ SCC in offspring by the same or discordant cancer in parents.

\section{The Swedish Family-Cancer Database}

The Swedish Family-Cancer Database, updated in 2000, includes persons born in Sweden after 1931 with their biological parents, totalling over 10.2 million individuals and organised in 3.2 million families (Hemminki et al, 1998; Hemminki and Vaittinen, 1998b). Cancers, including in situ skin cancers ('precancerous epithelial lesions'), were retrieved from the nation-wide Swedish Cancer Registry from years 1961 to 1998. The completeness of cancer registration in the 1970s has been estimated to be over $95 \%$, and is now considered to be close to $100 \%$. The percentage of cytologically or histologically verified cases of cancer has been close to $100 \%$ (Center for Epidemiology, 2000).

A four-digit diagnostic code based on the seventh revision of the ICD-7 has been used since 1958, together with a code for histological type (WHO/HS/CANC/24.1 Histology Code) in broad subgroups, such as adenocarcinoma and SCC, and we refer to this as the 'PAD code', for pathologic anatomic diagnosis. From year 1993 onwards ICD-O-2/ICD with histopathological data according to the Systematised Nomenclature of Medicine (SNOMED, http:// snomed.org) was used which we refer to as 'SNOMED'. Only the first invasive skin cancer or in situ cancer was considered, if not stated otherwise. Among discordant cancers in parents, the following ICD-7 codes were pooled: 140 (lip), 141 (tongue), $143-$ 148 (mouth, pharynx) and 161 (larynx), and 'leukaemia' 204-207 
(leukaemias), 208 (polycytemia vera) and 209 (myelofibrosis). Only adenocarcinoma was included for colorectum and only melanomo for eye cancer.

\section{Statistical analysis}

Family history information was collected on all first-degree relatives (parents, siblings and children) but only the parentoffspring relationship was used here because of the small numbers of affected sibling pairs. There were only one sibling pair with invasive SCC and four pairs with in situ SCC and these were included separately in the analysis of familial risk. Standardised incidence ratios, calculated as the ratio of observed $(\mathrm{O})$ to expected (E) number of cases, were used to measure the cancer risks for offspring by occurrence of cancers in their parents. The expected numbers of cancers were obtained by assuming that these persons had the same incidence as in the corresponding general population in the Database: offspring were included if their first primary cancer was diagnised at ages $0-66$ years, but no limit was placed on the age of parents. Tumor site-, sex-, 5-year-age- and 10-yearperiod-specific rates were applied to the relevant person-years at risk (Esteve et al, 1994). Person-years at risk were accumulated for each offspring beginning with the date of birth or January 1, 1961 and ending with the date of diagnosis of a first primary cancer, date of death, date of emigration, or December 31, 1998 whichever was earliest. Confidence intervals $(95 \%$ CI $)$ were calculated assuming that the numbers of cancer cases among offspring follow a Poisson distribution (Esteve et al, 1994). The population attributable fraction (PAF) of cases with a family history of invasive or in situ skin cancer was estimated as follows: proportion of cases with a family history $\times($ familial SIR -1$) /$ familial SIR, as defined by Miettinen (1974) and cited as formulas (16)-(21) by Rothman and Greenland (1998).

\section{RESULTS}

Table 1 presents details from the Family-Cancer Database of 1252 invasive skin SCCs in offspring and 17054 in parents, together with 2474 and 26999, respectively of in situ SCCs. Agestandardised incidence of invasive and in situ SCC is shown in Figure 1 for men and women. Male rates are almost two times higher for invasive cancer, but for in situ cancer there is no difference between the genders. The dramatic increase is seen for all rates, and particularly for in situ cancer, the incidence of which exceeds that of invasive SCC at the end of the study period.

Table 2 shows SIRs of 2.72 (95\% CI 2.01-3.61) for offspring invasive SCC when parents had invasive skin cancer, and 2.24 (1.69-2.92) when they had in situ SCC by the PAD code. According to the SNOMED code, the corresponding SIRs were
$3.35(2.33-4.66)$ and $2.90(2.09-3.93)$, respectively. The SIRs for offspring in situ SCCs were $2.38(1.89-2.95)$ and $2.40(1.98-2.88)$ when parents had invasive and in situ cancer, respectively. For the mixed type of in situ cancer (basal cell and SCC) when parents had in situ SCC, the SIR was 3.47 (1.72-6.23), which was the highest

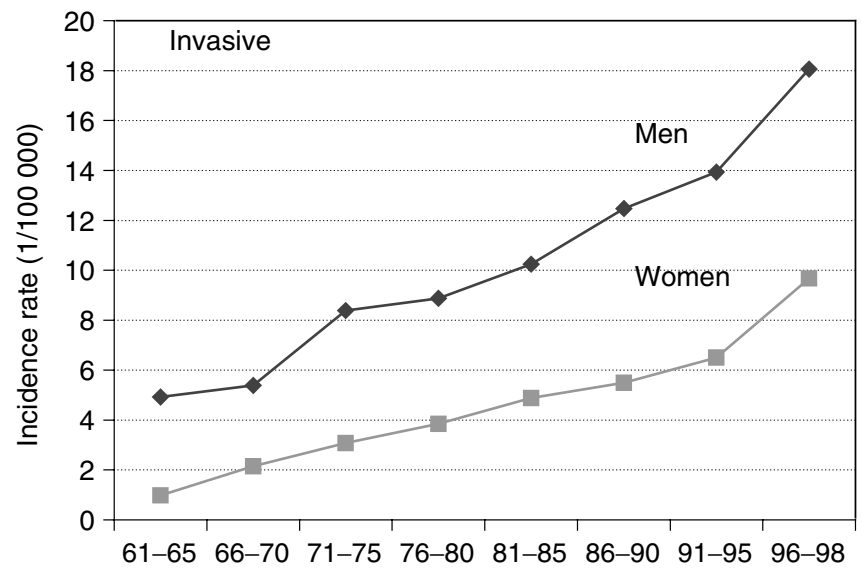

Year of diagnosis

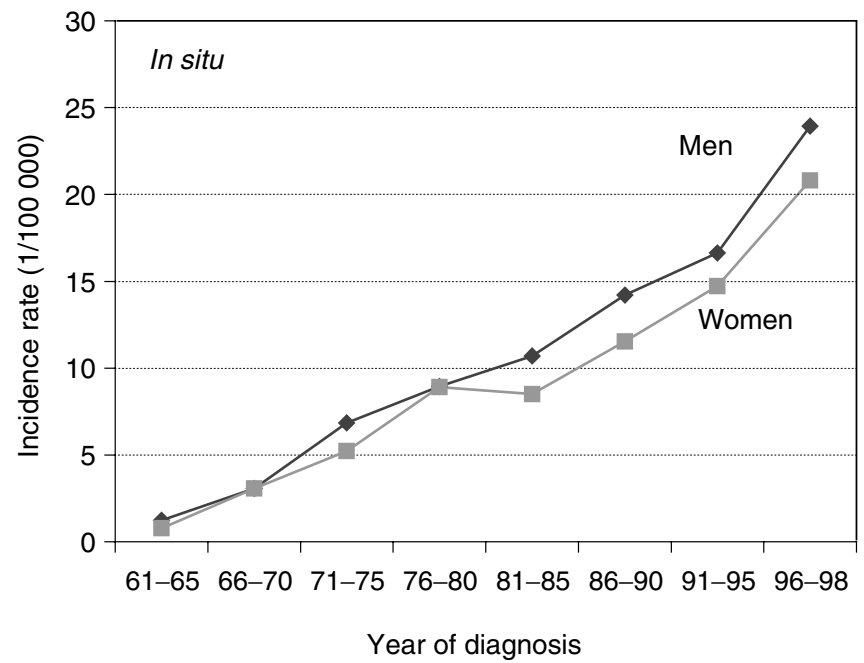

Figure I Age-standardised incidence rate of invasive and in situ SCC for the period 1961-1998 (standardised according to European standard population)

Table I Numbers of skin cancer by histopathological type

\begin{tabular}{|c|c|c|c|c|c|c|}
\hline \multirow[b]{2}{*}{ Cancer type ${ }^{a}$} & \multicolumn{3}{|c|}{ Number in offspring } & \multicolumn{3}{|c|}{ Number in parents } \\
\hline & Son & Daughter & Offspring & Father & Mother & Parents \\
\hline Invasive SSC & 728 & 524 & 1252 & 10945 & 6109 & 17054 \\
\hline Invasive SSC (SNOMED) & 513 & 346 & 859 & 4887 & 3272 & 8159 \\
\hline In situ SCC & 1248 & 1226 & 2474 & 13397 & 13602 & 26999 \\
\hline Mixed type & 88 & 77 & 165 & 849 & 544 & 1393 \\
\hline Actinic keratosis (SNOMED) & 63 & 72 & 135 & 3979 & 4116 & 8095 \\
\hline In situ SCC (SNOMED) & 483 & 415 & 898 & 619 & 741 & 1360 \\
\hline Bowen's disease (SNOMED) & 257 & 289 & 546 & 1588 & 1849 & 3437 \\
\hline
\end{tabular}

${ }^{a}$ Follow-up for SNOMED, 1993-1998. 
Table 2 Standardised incidence ratio for SCC in offspring of parents with skin cancer

\begin{tabular}{|c|c|c|c|c|c|c|c|c|}
\hline \multirow[b]{2}{*}{ Skin cancer in offspring ${ }^{a}$} & \multicolumn{4}{|c|}{ SCC in parent } & \multicolumn{4}{|c|}{ In situ SCC in parent } \\
\hline & 0 & SIR & $95 \%$ & $\mathbf{C l}$ & 0 & SIR & $95 \%$ & $\mathbf{C l}$ \\
\hline Invasive SSC & 48 & 2.72 & 2.01 & 3.61 & 55 & 2.24 & 1.69 & 2.92 \\
\hline Invasive SSC (SNOMED) & 35 & 3.35 & 2.33 & 4.66 & 42 & 2.90 & 2.09 & 3.93 \\
\hline In situ SCC & 83 & 2.38 & 1.89 & 2.95 & 116 & 2.4 & 1.98 & 2.88 \\
\hline In situ SCC (SNOMED) & 29 & 2.78 & 1.86 & 3.99 & 35 & 2.44 & 1.70 & 3.39 \\
\hline Mixed type & 2 & 0.88 & 0.08 & 3.25 & 11 & 3.47 & 1.72 & 6.23 \\
\hline Actinic keratosis (SNOMED) & 5 & 2.51 & 0.79 & 5.90 & 7 & 2.60 & 1.03 & 5.38 \\
\hline Bowen's disease (SNOMED) & 16 & 2.14 & 1.22 & 3.49 & 23 & 2.21 & 1.40 & 3.33 \\
\hline
\end{tabular}

aFollow-up for SNOMED, 1993-1998. Bold type: 95\% Cl does not include 1.00. O, observed; SIR, standardised incidence rate.

Table 3 Standardised incidence ratio for SCC in offspring of parents with skin cancer

\begin{tabular}{lrlll}
\hline Age group (y) & $\mathbf{0}$ & SIR & $\mathbf{9 5 \%}$ & $\mathbf{C I}$ \\
\hline $20-29$ & 5 & $\mathbf{3 . 3 2}$ & $\mathbf{1 . 0 5}$ & $\mathbf{7 . 8 1}$ \\
$30-39$ & 15 & $\mathbf{1 . 9 2}$ & $\mathbf{1 . 0 7}$ & $\mathbf{3 . 1 7}$ \\
$40-49$ & 71 & $\mathbf{2 . 3 1}$ & $\mathbf{1 . 8 1}$ & $\mathbf{2 . 9 2}$ \\
$50-59$ & 131 & $\mathbf{2 . 3 6}$ & $\mathbf{1 . 9 7}$ & $\mathbf{2 . 8 0}$ \\
$60-66$ & 37 & $\mathbf{2 . 1 5}$ & $\mathbf{1 . 5 2}$ & $\mathbf{2 . 9 7}$ \\
All & 259 & $\mathbf{2 . 2 9}$ & $\mathbf{2 . 0 2}$ & $\mathbf{2 . 5 9}$ \\
\hline
\end{tabular}

Bold type: $95 \% \mathrm{Cl}$ does not include 1.00. O, observed; SIR, standardised incidence rate.

SIR found. The SNOMED classification separated three larger groups of in situ cancers, actinic keratosis, in situ SCC and Bowen's disease with SIRs between $2.14(1.22-3.49)$ and 2.78 (1.86-3.99). Among a total of 1252 offspring with invasive skin SCC, $48(3.8 \%)$ had an affected parent and using this proportion and the familial SIR of 2.72 , the PAF for familial risk was $2.4 \%$. Similarly, 116 of $2474(4.7 \%)$ offspring with in situ tumour had a parent with in situ SCC and using 2.40 for the familial SIR, the PAF for in situ familial SCC was $2.7 \%$.

When invasive and in situ skin SCC were considered together (Table 3), 259 of 3586 (7.2\%) offspring with SCC had parents with SCC, resulting in an SIR of 2.29 (95\% CI $2.02-2.59)$ and a PAF of $4.1 \%$. In Table 3, age-specific data for familial skin SCC are also shown. The highest risk was noted at an early age of 20-29 years with SIR of $3.32(1.05-7.81)$, while at later ages the SIRs were between $1.92(1.07-3.17)$ and $2.36(1.97-2.80)$.

Multiple skin cancers in parents, including invasive and in situ SCC skin cancers (Table 4), conveyed an increased SIR to offspring when compared to those of parents with a single skin cancer. The SIR was $14.93(2.82-44.20)$ for offspring invasive SCC when a parent had two invasive and two in situ cancers, the comparable in situ SCC risk was 7.49 (1.41-22.18). However, the number of affected offspring was small when parents had multiple skin cancers.

Familial risks of SCC in offspring were analysed when parents had diverse invasive cancers (Table 5). Among the parental sites, the urinary bladder, prostate, skin melanoma, skin SCC and eye melanoma were associated with invasive SCC in offspring. For offspring in situ SCC, only parental melanoma and invasive SCC increased the risk. The data in Table 5 were derived from 46 comparisons among cancer sites, which could have resulted in 2 or 3 significant findings owing to chance alone. We found nine significant differences, of which seven were increases, suggesting that some increases were genuine.

\section{DISCUSSION}

The only previous study of familial skin SCC is that by Hemminki and Dong (2000a). Our present study is substantially larger, allowing analysis of both offspring and parents by the squamous cell histology. Some possible biases need to be considered. The quality of the Swedish Cancer Registry is high, but the marked increas particularly of in situ cases (Figure 1) raises the possibility that reporting to the Registry has improved over the time. All registered cases of SCC were verified by histology or cytology (Center for Epidemiology, 2000). At present there may be an increased concern and alertness in families with affected individuals and may be seeking medical opinion about treatment more often than in the past. This cannot be excluded in Sweden for SCC but as the diagnoses are always confirmed by histology or cytology, the effect would be a lead-time bias rather than a false diagnosis (Hemminki and Vaittinen, 1998a; Wassberg et al, 1999). The numbers of affected types of families argue against bias: as compared to 259 affected parent-offspring families with any skin SCC, there was only one sibling pair with invasive SCC and four pairs with in situ SCC. Considering the number of skin tumours in the 3.2 million families of the Database, the number of affected sibling pairs was within expectations.

The data on family clustering of skin SCC show a strong effect with a SIR of 3.35 for concordant invasive SCC in parents and offspring, based on the SNOMED codes used during 1993-1998 although the corresponding risk for the whole period, 1961-1998, was somewhat lower at 2.72 . These risks, together with the very high SIRs from multiple tumours in the parental probands, such as 7.25 from three tumours and 14.93 from four tumours provide strong evidence for heritable effects in skin SCC. The familial SIRs for in situ SCC were also increased but tended to be lower than those for invasive tumours, which could imply a degree of diagnostic inconsistency. Both invasive and in situ form were represented in the same families giving further evidence of their biological similarity. The mixed in situ tumour with basal and squamous cell elements showed the highest SIR of all comparisons, 3.47 from parental in situ SCC. The three types of in situ tumours, in the SNOMED classification were comparable in their familial presentation, as far as the number of cases allowed any conclusions. In the dermatological literature there has been a long standing controversy as to the distinction of the different kinds of in situ tumours and whether they represent different biological entities between each other and between them and invasive forms (MacKie, 1996; Heaphy and Ackerman, 2000; Rees, 2002).

When invasive and in situ skin cancer were considered together, familial risk was higher at young ages and the PAF of familial SCC was $4.1 \%$. Familial clustering may be because of inherited and/or environmental factors. One way to assess the shared environ- 
Table 4 Standardised incidence ratio for SCC in offspring of parents with skin cancers

\begin{tabular}{|c|c|c|c|c|c|c|c|c|}
\hline \multirow[b]{2}{*}{ Parental SCC } & \multicolumn{4}{|c|}{ SCC in offspring } & \multicolumn{4}{|c|}{ In situ SCC in offspring } \\
\hline & 0 & SIR & $95 \%$ & $\mathbf{C l}$ & $\mathbf{0}$ & SIR & $95 \%$ & $\mathbf{C l}$ \\
\hline I invasive & 42 & 2.55 & 1.84 & 3.45 & 71 & 2.18 & 1.70 & 2.74 \\
\hline I in situ & 46 & 2.14 & 1.56 & 2.85 & 97 & 2.28 & 1.85 & 2.78 \\
\hline I invasive and I in situ & 3 & 1.83 & 0.34 & 5.41 & 9 & 2.77 & 1.26 & 5.28 \\
\hline 2 invasive & 6 & 4.09 & 1.47 & 8.96 & 12 & 4.10 & 2.11 & 7.19 \\
\hline 2 in situ & 9 & 2.99 & 1.36 & 5.70 & 18 & 3.02 & 1.78 & 4.78 \\
\hline 2 invasive and 1 in situ & 4 & 7.25 & 1.89 & 18.74 & 6 & 5.43 & 1.96 & 11.90 \\
\hline 1 invasive and 2 in situ & 3 & 4.29 & 0.81 & 12.69 & 6 & 4.30 & 1.55 & 9.42 \\
\hline 2 invasive and 2 in situ & 3 & 14.93 & 2.82 & 44.2 & 3 & 7.49 & 1.41 & 22.18 \\
\hline
\end{tabular}

Bold type: $95 \% \mathrm{Cl}$ does not include 1.00 . O, observed; SIR, standardised incidence rate.

Table 5 Standardised incidence ratio for SCC in offspring by type of parental cancer ${ }^{\mathrm{a}}$

\begin{tabular}{|c|c|c|c|c|c|c|c|c|}
\hline Parental invasive & 0 & SIR & $95 \%$ & Cl & 0 & SIR & $95 \%$ & Cl \\
\hline Upper aerodiagestive tract & 16 & 1.13 & 0.64 & 1.84 & 21 & 0.70 & 0.44 & 1.08 \\
\hline Oesophagus & 7 & 1.38 & 0.55 & 2.87 & 6 & 0.56 & 0.20 & 1.23 \\
\hline Stomach & 28 & 0.77 & 0.51 & 1.11 & 66 & 0.85 & 0.66 & 1.08 \\
\hline Colon & 77 & 1.13 & 0.89 & 1.41 & 118 & 0.82 & 0.68 & 0.99 \\
\hline Lung & 46 & 1.11 & 0.81 & 1.48 & 85 & 0.99 & 0.79 & 1.22 \\
\hline Breast & 60 & 0.99 & 0.76 & 1.28 & 110 & 0.88 & 0.72 & 1.06 \\
\hline Cervix & 18 & 1.48 & 0.88 & 2.35 & 15 & 0.60 & 0.34 & 0.99 \\
\hline Endometrium & 17 & 1.13 & 0.66 & 1.81 & 21 & 0.67 & 0.42 & 1.03 \\
\hline Ovary & 10 & 0.70 & 0.33 & 1.30 & 26 & 0.88 & 0.58 & 1.30 \\
\hline Prostate & 106 & 1.24 & 1.01 & 1.50 & 180 & 1.00 & 0.86 & 1.16 \\
\hline Kidney & 19 & 0.92 & 0.55 & 1.44 & 37 & 0.86 & 0.60 & 1.19 \\
\hline Thyroid gland & 6 & 1.39 & 0.50 & 3.04 & 7 & 0.78 & 0.31 & 1.61 \\
\hline Endocrine glands & 10 & 1.14 & 0.54 & 2.10 & 25 & 1.40 & 0.90 & 2.06 \\
\hline Non-Hodgkin's lymphoma & 16 & 1.02 & 0.58 & 1.67 & 31 & 0.96 & 0.65 & 1.36 \\
\hline Myeloma & 5 & 0.50 & 0.16 & 1.19 & 27 & 1.29 & 0.85 & 1.88 \\
\hline Leukaemia & 15 & 0.88 & 0.49 & 1.45 & 40 & 1.11 & 0.79 & 1.52 \\
\hline Total & 616 & 1.13 & 1.04 & 1.22 & 1087 & 0.96 & 0.90 & 1.02 \\
\hline
\end{tabular}

${ }^{a}$ Cancer sites with less than five cases are excluded. Bold type: The lower 95\% Cl does not include 1.00. O, observed; SIR, standardised incidence rate.

mental factors involving exposure to sun is to compare the correlation of skin SCC between spouses and the fact that no such correlation has been found in this Database and this comparison suggests that heritable factors are more important than environmental factors in the familial aggregation of skin cancer (Hemminki et al, 2001a; Hemminki and Jiang, 2002). Moreover, in a separate study we have found that familial risk can be found both in sun-exposed and covered sites, adding to the evidence that sun exposure alone does not explain the familial aggregation (unpublished data). The molecular basis of SCC is not fully understood (Reese, 1998, 2002; Rees, 2002), mutations in the PTC gene, common in basal cell carcinoma, being rare in SCC. Although $p 53$ and $\mathrm{H}$-ras mutations are common they may not be the initial events in skin carcinogenesis. Squamous cell carcinoma is not a feature of Li-Fraumeni families who have a germ-line mutation in the $p 53$ gene (Malkin, 1998). Since sun exposure is an established risk factor of skin cancer, at least part of the familial risk may be explained by cumulative exposure to sun, or by an inherited trait of skin type. SCC is a major complication in two rare recessive syndromes: xeroderma pigmentosum and Bloom syndrome, involving defects in DNA excision repair and DNA helicase, respectively (German and Ellis, 1998; Balajee and Bohr, 2000; de Boer and Hoeijmakers, 2000). Since these syndromes are recessive, they would not be observed when comparing familial cancers between parents and offspring. The important question of a possible cancer risk in the heterozygous carriers in the DNA repair gene defects awaits further study.

Melanoma was the only discordant tumour that associated with invasive and in situ skin SCC, an association also noted in melanoma families (Hemminki et al, 2001b). In the present study, the excess familial risks for invasive and in situ SCC in offspring were 2.2 and 2.6 times higher, respectively, when a parent had the 
same cancer as compared to a parent with melanoma. Solar irradiation affects SCC and melanoma in different ways and the distribution of affected body parts also varies (English et al, 1997). However, considering the much higher risks from parental SCC than melanoma, some contribution by ultraviolet radiation to the SCC-melanoma association is likely. Even more interesting was the association of invasive SCC (SIR 3.26) with eye melanoma, constituting some $80 \%$ of intraocular tumours, for which sun ultraviolet radiation has been considered only a weak risk factor (English et al, 1997). Sweden is located between latitudes 55 and $70^{\circ}$, implying that the prevailing low solar altitude causes a relatively long-lasting ultraviolet radiation exposure of the retina. A further point is that eye melanoma does not appear to associate with familial cutaneous melanoma (Sinilnikova et al, 1999; Hemminki and Jiang, 2001). These data suggest that solar irradiation is the common denominator for the aggregation of skin SCC, cutaneous melanoma and ocular melanoma, and this is supported by recent reports (Shors et al, 2002; Vajdic et al, 2002; Hemminki et al, 2003). The significance of other associations between parental prostate and bladder cancers with invasive SCC remains unclear.

\section{REFERENCES}

Balajee A, Bohr V (2000) Genomic heterogeneity of nucleotide excision repair. Gene 250: 15-30

Center for Epidemiology (2000) Cancer Incidence in Sweden 1998, pp 1 114, Stockholm

de Boer J, Hoeijmakers JHJ (2000) Nucleotide excision repair and human syndromes. Carcinogenesis 21: $453-460$

Dong C, Hemminki K (2001a) Modification of cancer risks in offspring by sibling and parental cancers from 2112616 nuclear families. Int J Cancer 91: $144-150$

Dong C, Hemminki K (2001b) Second primary neoplasms in 633964 cancer patients in Sweden, 1958-1996. Int J Cancer 93: 155-161

English D, Armstrong B, Kricker A, Fleming C (1997) Sunlight and cancer. Cancer Causes Control 8: 271-283

Esteve J, Benhamou E, Raymond L (1994) Statistical Methods in Cancer Research, Vol. 128. IARC Scientific Publication. Lyon: IARC

Frisch M, Melbye M (1995) New primary cancers after squamous cell skin cancer. Am J Epidemiol 141: 916-922

German J, Ellis N (1998) Bloom syndrome. In The Genetic Basis of Human Cancer, Vogelstein B, Kinzzler K (eds) pp 301-315. New York: McGrawHill.

Heaphy M, Ackerman A (2000) The nature of solar keratosis: a critical review in historical perspective. J Am Acad Dermatol 43: $138-150$

Hemminki K, Dong C (2000a) Familial relationships in squamous cell carcinoma of the skin. Epidemiology 11: 309-314

Hemminki K, Dong C (2000b) Primary cancers following squamous cell carcinoma of the skin suggest involvement of Epstein - Barr virus. Letter to editor. Epidemiology, 11: 94

Hemminki K, Dong C (2000c) Subsequent cancers after in situ and invasive squamous cell carcinoma of the skin. Arch Dermatol 136: $647-651$

Hemminki K, Dong C, Vaittinen P (1999) Familial risks in cervix cancer: is there a hereditary component? Int J Cancer 82: 775-781

Hemminki K, Dong C, Vaittinen P (2001a) Cancer risks to spouses and offspring in the Family Cancer Database. Genet Epidemiol 20: $247-257$

Hemminki K, Jiang Y (2001) Association of ocular melanoma with breast cancer but not with cutaneous melanoma: results from the Swedish Family Cancer Database. Int J Cancer 94: 907 -909

Hemminki K, Jiang Y (2002) Cancer risks among long-standing spouses. $\mathrm{Br}$ J Cancer 86: $1737-1740$

Hemminki K, Lönnstedt I, Vaittinen P (2001b) A population-based study of familial cutaneous melanoma. Melanoma Res 11: 133-140

Hemminki K, Vaittinen P (1998a) Familial risks in in situ cancers from the Family Cancer Database. Cancer Epidemiol Biomarkers Prev 7: 865-868
In contrast to the scarcity of familial data on skin SCC, there are many studies published on second cancers following skin SCC (Frisch and Melbye, 1995; Levi et al, 1996, 1997, 1998; Wassberg et al, 1999; Dong and Hemminki, 2001b; Hemminki and Dong, 2000b, c; Milan et al, 2000). These have shown a consistent link between SCC and melanoma, while an association between skin and eye cancer has been noted (Milan et al, 2000). Many studies on second cancers have found an excess of cancers associated with immunological disturbances and immunosuppression, including lymphoma, and lip (oral), cervical and connective tissue cancers (IARC, 1996). However, the present results provide no support for the role of impaired immune function.

In summary, the present data on relatively young individuals provided evidence that there is an underlying hereditary susceptibility explaining at least a part of the familial clustering of skin SCC. Familial risks between invasive and various in situ forms of SCC appear to be similar and in many families different forms of SCC are manifested. The association of skin SCC with cutaneous and ocular melanoma may be largely because solar irradiation.
Hemminki K, Vaittinen P (1998b) National database of familial cancer in Sweden. Genet Epidemiol 15: 225-236

Hemminki K, Vaittinen P, Kyyrönen P (1998) Age-specific familial risks in common cancers of the offspring. Int J Cancer 78: $172-175$

Hemminki K, Zhang H, Czene K (2003) Association of first ocular melanoma with subsequent cutaneous melanoma: results from the Swedish Family Cancer Database. Int J Cancer 104: $257-258$

IARC (1990) Cancer: Causes, Occurence and Control, Vol. 100. IARC Scientific Publications. Lyon: IARC

IARC (1995) Human papillomaviruses, Vol. 64. IARC Monographs on the Carcinogenic Risks to Humans. Lyon: IARC

IARC (1996) IARC Monographs on the Evaluation of Carcinogenic Risks to Humans Vol. 67. Human immunodeficiency Viruses and Human T-cell Lymphotrophic Viruses. Lyon: IARC

Levi F, Randimbison L, La Vecchia C (1998) Nonmelanomatous skin cancer following cervical, vaginal, and vulval neoplasms: etiologic association. $J$ Natl Cancer Inst 90: 1570-1571

Levi F, Randimbison L, La Vecchia C, Erler G, Te V (1997) Incidence of invasive cancers following squamous cell skin cancer. Am J Epidemiol 146: $734-739$

Levi F, Randimbison L, Vecchia C, Franceschi S (1996) Incidence of invasive cancers following carcinoma in situ of the cervix. Br J Cancer 74: $1321-1323$

MacKie R. (1996) Skin Cancer London: Martin Dunetz

Malkin D (1998) The Li-Fraumeni syndrome. In The Genetic Basis of Human Cancer, Vogelstein B, Kinzler K (eds) pp 393-407. New York: McGraw-Hill

Miettinen O (1974) Proportion of disease caused or prevented by a given exposure, trait or intervention. Am J Epidemiol 99: 325-332

Milan T, Pukkala E, Verkasalo PK, Kaprio J, Jansen CT, Koskenvuo M, Teppo L (2000) Subsequent primary cancers after basal-cell carcinoma: a nationwide study in Finland from 1953 to 1995. Int J Cancer 87: $283-288$

Reese J (1998) Skin cancer (Gorlin's syndrome) In The Genetic Basis of Human Cancer, Kinzzler K (ed) pp 527-536. New York: McGrawHill

Reese J (2002) Skin cancer (including nevoid basal cell carcinoma syndrome) In The Genetic Basis of Human Cancer, Kinzzler K (ed) pp 539-548. New York: McGraw-Hill

Rothman K, Greenland S (1998) Modern Epidemiology. Philadelphia: Lippincott-Raven

Shors A, Iwamoto S, Doody D, Weiss N (2002) Relationship of uveal and cutaneous malignant melanoma in persons with multiple primary tumors. Int J Cancer 102: 266-268 
Sinilnikova O, Egan K, Quinn J, Boutrand L, Lenoir G, Stoppa-Lyonnet D, Desjardis L, Levy C, Goldgar D, Gragoudas E (1999) Germline brca2 sequence variants in patients with ocular melanoma. Int $J$ Cancer 82: $325-328$

Vajdic C, Kricker A, Giblin M, McKenzie J, Aitken J, Giles G, Armstrong B (2002) Sun exposure predicts risk of ocular melanoma in Australia. Int $J$ Cancer 101: 175-182

Wassberg C, Thorn M, Johansson AM, Bergstrom R, Berne B, Ringborg U (2001) Increasing incidence rates of squamous cell carcinoma of the skin in Sweden. Acta Derm Venereol 81: 268-272

Wassberg C, Thörn M, Yuen J, Ringborg U, Hakulinen T (1999) Second primary cancers in patients with squamous cell carcinoma of the skin. Int J Cancer 80: $511-515$ 